\title{
Constructions of frailty in the English language, care practice and the lived experience
}

\author{
AMANDA GRENIER*
}

\begin{abstract}
The way frailty is conceptualised and interpreted has profound implications for social responses, care practice and the personal experience of care. This paper begins with an exegesis of the concept of frailty, and then examines the dominant notions of frailty, including how 'frailty' operates as a 'dividing-practice' through the classification of those eligible for care. The definitions and uses of 'frailty' in three discursive locations are explored in: (a) the Oxford English Dictionary, (b) the international research literature, and (c) older women's accounts of their lived experience. Three distinctive discourses are found, and applying a Foucauldian analysis, it is shown that the differences reflect overlaps and tensions between biomedical concepts and lived experiences, as well as negative underlying assumptions and 'subjugated knowledge'. The concept of frailty represents and orders the context, organisational practices, social representations and lived experiences of care for older people. The evidence suggests that if, as the older women's accounts recommended, socially- and emotionally-located expressions of frailty were recognised in addition to the existing conceptions of risk of the body, frailty might no longer be thought of primarily as a negative experience of rupture and decline. To encourage this change, it is suggested that practice focuses on the prevention of frailty and associated feelings of loss, rather than reinforcing the feelings and experiences which render a person 'frail'.
\end{abstract}

$\boldsymbol{K E} \boldsymbol{Y} \boldsymbol{W O R} \boldsymbol{D} \boldsymbol{S}$ - frailty, older people, discourse, home-care, lived experience.

\section{Introduction}

It is difficult to determine when the concept of 'frailty' attained its present prominence in general, gerontological and policy discourse. No specific event marks its emergence in the vocabulary applied to long-term care for older people. Appearing in demography in the late i97os (Vaupel, Manton and Stallard 1979), the current use of the term with reference to the care for older persons probably gained impetus with the promotion of managed

* School of Social Work, McGill University, Montreal, Canada. 
care in the United States during the I980s (see Rubenstein et al. 1984). Since then, the concept has gained popularity in international gerontological research, and in policy and practice contexts. In western societies, at least, 'frailty' is currently a major discursive concept in these fields.

There has, however, been little critical reflection on the definition and use of the term, and its understanding differs by care discipline and discursive location (Robine et al. 2005). Frailty generally connotes a sense of physical weakness that results from a particular medical, physical or social limitation (Rockwood et al. I994, I996), as well as increased risks for morbidity, mortality or loss of autonomy (Morley, Perry and Miller 2002; Schmaltz et al. 2005). In care settings, frailty refers to an older person at risk or with a particular profile, such as those aged 85 or more years with previous hospitalisation (Vellas et al. 2000). The way in which frailty among older people is conceptualised and interpreted has profound implications for policies, organisational practices and personal experiences of care across the lifecourse. Drawing on the identified definitions and uses of frailty, this paper exposes the term's underlying assumptions, tensions and contradictions. Given the confusions that the term produces, the good sense of its application to older people is questioned.

\section{Assessing frailty: a 'dividing practice' in care for older persons}

This paper reports a Foucauldian analysis of discourse and practice that has made particular use of the notions of 'dividing practices' and 'subjugated knowledge' (Foucault 1972, I994a, I994b). 'Dividing practices' refer to the division of subjects and processes of objectification that occur either during or as a result of naming and classification. 'The subject is either divided inside himself or divided from others. This process objectivizes [sic] him. Examples are the mad and the sane, the sick and the healthy, the criminals and the "good boys" (Foucault I982: 208). In making these distinctions, particular types of knowledge and experience (e.g. functional decline) are accepted, while others (e.g. strengths and abilities) are 'subjugated' or dismissed (Foucault I980: 78-108). The focus of such an analysis is therefore upon how language operates in organisational practices - the discursive locations of power. This analysis aims to uncover the discourses that have come to be accepted as 'truth', to expose classification as a powerful act, and to reveal underlying assumptions that operate when such powerful concepts are adopted.

The practice of assessing 'frailty' in formal care may be considered an example of a 'dividing practice' (Foucault I982), which divides (or classifies) in order to provide or restrict access to care. Those who make assessments 
separate frail and non-frail subjects to facilitate or block access to services. To target services towards those at greatest risk, assessment involves making distinctions between the abnormal (e.g. unable) and the normal (e.g. able). Categorisation differentiates objects (in this case, clients or people), and shapes the service response to the different categories. Those assigned the status of 'frail' become eligible for public home-care services, and those not so assigned remain ineligible. Being considered a frail subject thus becomes an important step in the process of having one's needs met. A brief exegesis of frailty partly explains today's dominant usage in Western care practice.

\section{'Frailty' in demography and health-services research}

A brief review of the usage of frailty in Western research literature reveals that the concept of frailty is intricately linked with powerful discourses on longevity and the dominant managed-care model, and plays a central role in macro- and micro-level policy planning and service delivery. The study of frailty is most evidently the province of both applied demography (Barbi, Caselli, and Vallin 2003; Vaupel, Manton and Stallard I979; Yashin and Iachine I997), and health and clinical medicine (Bortz I993, I997, 2002; Fried and Walston I999; Fried et al. 200I; Rockwood et al. I994, I996). Demographic and public-health studies generally focus on population variations while, by contrast, most clinical studies focus on individual interventions.

Demographic research on frailty is firmly rooted in predicting longevity (i.e. the duration of the human life-span) and mortality rates (Alter i995; Yashin and Iachine I997). Vaupel, Manton and Stallard (I979:440) introduced the proposition that the nature and severity of frailty are predictors of mortality, although 'the exact moment of death will be determined by various individual differences beyond population group, age, date-of-birth and frailty level'. The proposition shifted demographic interests from the number of people reaching the biological limit (i.e. the rates and causes of mortality) to individual differences and the possibility that people of the same generation experience different types of vulnerability to death (Fries I980; Vaupel et al. I979; Vaupel and Yashin 1985). "When mortality is high, persons who are relatively more "frail" tend to die at younger ages, and the distribution of frailty among survivors at older ages is quite different from the distribution of frailty at birth' (Alter I995: 329). From a demographic perspective, 'a frail individual is one with higher-thanaverage mortality risk, and a robust individual is one with lower-thanaverage risk' (Foster ig9i : 636). 
The emphasis on heterogeneity sparked debates about longevity and set the stage for the current interest in frailty as individual risk. Demographic studies integrated environmental and personal risks into the study of ageing, survival and mortality (Barbi, Caselli, and Vallin 2003; Fries 1980; Manton and Stallard I984; Vaupel, Yashin and Manton ig88; Yashin and Iachine 1997); and demographers debated whether longevity was based on a genetically-determined and inherited maximum life-span (e.g. biological limits), or inheritance and acquired frailties. In other words, they integrated 'individual susceptibility to disease and death [into] the analysis of survival data' (Yashin and Iachine 1997: 43-4), and understanding elaborated from a sole concern with the impact of 'population shocks', or the shared history of crises, to incorporate individual variations, including inherited risks and the variable hazards experienced by a population (Barbi, Caselli and Vallin 2003; Foster I99I). Explanations of longevity and mortality changed in conception and form, from calibrations of age-based risks in populations to multivariate models of the outcomes of an individual's multiple risks and hazards (Bortz I997; Foster I99I; Sage et al. I987; Vaupel I988). The latter required and had direct connections with clinical studies on the variables responsible for vulnerability and risk.

Clinical research on frailty focuses on predicting risks, targeting clinical interventions and responding to adverse outcomes in care (and some extend to evaluations of the cost of care) (Jones et al. 2004). In clinical settings, frailty is considered as a syndrome, and frailties as signs that present as functional impairments, disabilities and co-morbidities (Schirm I989). Frailty has been used to predict the utilisation of long-term care services, to target interventions, and to reduce treatment and administrative costs (Branch et al. 1988; Brody et al. 2002; Rubenstein et al. 1984). In this conception, frailty has come to be seen as a composite indicator of the probabilities of death, nursing-home entry, service utilisation and the attendant costs.

Coinciding with the 'mixed economy' of care that was promoted during the Ig8os, the clinical use of the concept of frailty paralleled the shift from a social responsibility for care to market provision (see Neysmith and MacAdam 1999). This includes the practice of managed-care using standard assessments of eligibility (see Edinburgh and Aldredge 1995; Shortell and Kaluzny 1994), and the primacy of the managerial principles of effectiveness, efficiency, cost reduction, and related performance and outcomes measurement (Armstrong 2000; Edinburgh and Aldredge 1995; Kane 2000). ${ }^{1}$ Three points about the adoption of managerial principles are important in the analysis of frailty. First, ideas about care provision shifted from universal and rights-based provision to targeting those in most need 
(see Means, Richards and Smith 2003). Second, need is most commonly interpreted as risk (see Beck I992). Third, risk is most often defined by professionals and by them restricted to standard measures of impairment and function (for a discussion of risk-based planning see World Health Organisation 2002: 27-45). The assessment of frailty is currently located within this shifting context of care. Since Kaufman's (I994) original analysis of frailty in the United States, the use of frailty has spread to several other countries that have adopted a managed-care model (e.g. Canada and the United Kingdom), and has come to play a key role in the assessment of risk and the allocation of public home-care services.

While the demographic focus on longevity sparked interest in the concept of frailty, its growing popularity and utility in the US managed-care model of the Ig8os seems to have been the launch pad for its current widespread administrative and clinical use in care practice for older people. ${ }^{2}$ Moreover, clinical accounts of frailty as functional impairment and risk appear to have become the dominant discourse on frailty, as reflected in the voluminous material on frailty from biomedical and clinical perspectives, and from the concept's prominence in policy and planning documents that are responses to population ageing. That the clinical definition of frailty has become prevalent in the western practice of formal care is unsurprising, considering that most demographic research is macrolevel, and therefore encourages national comparisons and international knowledge-exchange on longevity and population statistics. The way frailty is articulated at the macro- and micro-levels establishes the ways in which individuals in need of care (or at risk) are treated, and the extent to which resources are (or are not) channelled to them. Yet, the current micro-level conceptualisation overlooks crucial aspects of experience and presents contradictions for older people. These can be understood by turning to other discourses of the concept of frailty.

\section{Discourses of frailty: care concepts and practices}

Three locations of discourse on frailty have been examined for this paper: (a) the Oxford English Dictionary, (b) international published research literature on the concept of 'frailty', and (c) a narrative study on older women's accounts of frailty. The three in aggregate are neither comprehensive nor exhaustive, but reveal underlying assumptions, tensions and contradictions about the conceptualisation of frailty among older people. The discussion begins with a brief review of the meaning of frailty in general English-language discourse. 


\section{Lexical variations of frailty}

The Oxford English Dictionary (OED) records the etymology, past and current meanings and pronunciation of English-language words. It provides insights into the intended and actual daily use of 'frailty' in the language, as well as a standard frame of reference for the way in which words are used internationally. The OED definitions provide guidance on the usage of 'frailty' outside gerontology and by formal carers of older people. According to the second edition of ig89, the contemporary (and recent) meanings of the adjective frail and the noun frailty are:

FRAIL: I. Liable to break or be broken; easily crushed or destroyed. b. Of immaterial things, sometimes with conscious metaphor: Subject to casualties, liable to be suddenly shattered, transient. 2. Weak, subject to infirmities; wanting in power, easily overcome. 3. Morally weak; unable to resist temptation; habitually falling into transgression. ${ }^{3}$

FRAILTY: I. Liability to be crushed or to decay, either in a material or immaterial sense; perishableness, weakness; also, a frail feature or spot, a flaw. Now rare. 2. Moral weakness; instability of mind; liability to err or yield to temptation. b. A fault arising from infirmity; a 'weakness'.

This definition of frailty reveals an association with both physical and mental capacity (liable to break or be broken; subject to casualty; morally weak), and connects frailty with powerlessness and weakness (wanting in power), with impairment (subject to infirmities), and with an implication of blame (a fault arising from infirmity). The connection between fault and infirmity may be interpreted in a purely mechanistic or unconscious physiological sense, but introduces an inherent social devaluation. Overall, the OED renders frailty, or being frail, as a negative condition with various physical, social and moral dimensions. Many European languages have a variant of the term, with subtle differences in the meaning of the concept, while in any country or language the usage in organisational practice reflects cultural norms and service-delivery models. For example, in bi-lingual Montréal, Québec, English-speaking health- and social-care staff use frailty, while French-speaking staff use dependence or perte d'autonomie [loss of autonomy] when referring to a vulnerable person, despite the currency in the French language of frêle, and despite the enthusiusm in French-language research to analyse the prevalence and forms of frailty. While the concepts used in care practice invoke slightly different connotations, they also reveal common associations and attributed qualities. Whichever the term applied, the process of assessment is the same-concepts of functional mobility and impairment, such as frailty, play a key role in meeting the patient's needs. 


\section{Frailty in academic writing}

A comprehensive review was conducted of publications in the medical, health and social sciences between 1998 and 2002 that used the concept of frailty. Although numerous articles make reference to frailty when referring to a sub-group of older people (e.g. Eales, Keating and Damsma 200I), the review covered only the papers that included conceptual discussion. Beginning with the scientific and medical conceptions, it was found that the literature is dominated by biomedical articles that treat frailty as a class or category of problems or disorders. Frailty is referred to as an 'age-related inability to respond adequately to stress' (Rockwood et al. I994; Bowsher et al. 1993; Campbell and Buchner 1997), and as 'a multi-dimensional construct indicated by the presence of two or more medical or functional problems' (Fried et al. 200 ; Fried and Watson I999; Hamerman I999; Rockwood, Stolee and McDowell i996; Strawbridge et al. i998). ${ }^{4}$ Prominent concerns in the medical (or clinical) literature centre on whether frailty is a result of natural decline (i.e. the ageing process) (Michel 200I), of disease (Bortz I993; Bortz 2002), of lifestyles (Bortz 2002), or of associations between health and impairment (Raphael et al. I995; Rockwood et al. 1994). While most medical papers focus on the deficits or impairments of the body, commonly using quantitative performance indicators (Brown et al. 2000; Markle-Reid and Browne 2003; Studenski et al. 2004), some explicate the physical (e.g. nutrition, mobility) and mental (e.g. personality, affect) components of frailty, and some extend to an interest in social influences (e.g. family support, income and education) (Rockwood et al. 1994, 1996), environmental factors (Raphael et al. 1995) and experiential variables (Bowsher et al. I993; Michel 200i).

Alongside the concern with causation, the medical literature indicates that the concept of frailty has clinical relevance. Clinicians state that they can easily distinguish a frail from a non-frail older person and can predict the associated risks, such as hospitalisation, falls, and a decreased ability to perform the activities of daily living (Fried and Watson I999; Fried et al. 200I). This literature also describes the living circumstances of frail older people that raise the risks of physical injury, decreased mobility and function, co-morbidity (Campbell and Buchner i997; Rockwood et al. I994, 1996), and death (Brody et al. 2002; Morley, Mitchell and Miller 2002). It also makes links between the deficits of the body and the concerns in health economics about increased care demands and the 'over' use of health-care services (Hamerman i999).

Turning to the social conceptions of frailty, many social science contributions argue that frailty is socially constructed (Gadow ig86; Kaufman I994; Kaufman and Becker I996; Lustbader 2000), and focus on health-care 
practices and the meanings of experiences related to frailty (i.e. impairment, disability, decline). Much of this literature is critical of the dominance of the biomedical perspective in health-care practice. As one example, 'the process by which frailty is culturally constructed in the health-care context takes a certain form: it is a transformation from lived problems to diagnosis, then to treatment plan, then to rules about what ought to be done, and finally to negotiated compliance' (Kaufman and Becker i996: 59). The general concern is that narrow biomedical conceptions of 'frailty as risk' reduce the conception of care to objective classifications of need. Morley et al. (2002) argued that social factors (e.g. low income, low education, and lack of family, religious or other social supports) condition the impacts of frailty, whatever its severity. Social science contributions also suggest that frailty has implications for identity and self perception (Atchley I99I; Gadow I986; Taylor 1992); creates a dichotomy between the body and the self (Gadow I986); and has negative effects, including interrupted continuity and loss, problematic power relations (e.g. being at the mercy of care-givers), and depersonalisation (Atchley I99I; Lustbader 2000). ${ }^{\mathbf{5}}$

The social science literature points to conflicts between the dominant biomedical conceptualisation and older people's experiences, and challenges the presumed connections between frailty, decline and death (Gadow I986; Lustbader 2000; Taylor 1992). It acknowledges, however, that the recognition of a syndrome of frailty helps practitioners identify a patient's problems, and for older people to be advised, helped to adapt (Kaufman and Becker 1996), ${ }^{6}$ to see meaning in their experience (Becker I994; Taylor I992), and to become involved in policy and practicedevelopment processes (Barnes and Bennett 1998). ${ }^{7}$ Nevertheless, there is a clear difference between the vocabulary used by older people and professionals. Studies have found that older people do not use frailty to describe their own experiences (Grenier 2005; Kaufman I994; Kaufman and Becker 1996), and that that experiences linked with frailty provide various opportunities to embrace the body (Gadow I986), to create opportunities for strengthened relationships with family (Lustbader 2000), to provide time and space in which to narrate experiences of life and death (Taylor 1992), and to establish a terrain upon which autonomy and self are negotiated (Grenier and Hanley 2007; Kaufman and Becker I996). While many of these themes were articulated Io or more years ago, they continue in the usage of frailty today.

\section{Older women's understanding and use of frailty ${ }^{8}$}

The primary research element of the study explored how I2 Englishspeaking older women in Montreal, Quebec, made meaning of their 
experiences of frailty, disability and decline in their everyday life. ${ }^{\mathbf{9}}$ The sample was stratified in line with the classification of frailty used in formal home-care practice in Quebec, and to reflect the diversity of urban public services. ${ }^{10}$ Of the 12 , six were considered frail by the care services (i.e. according to clinical judgement and eligibility guidelines), and six women were not (and were not current service recipients). The interviews were unstructured; the women were asked to talk about themselves, and questions about their interpretations of 'frailty' were interjected only late in the interview. The results presented in this paper are drawn from the participants' specific responses to my inquiries about frailty.

The older women referred to frailty in various ways, ranging from an observable physical state, through the experience of vulnerability and negative social assumptions, to its associations with crisis events. The physical descriptions related to appearance and health, the most common being references to 'being small' or 'skinny'. Frailty was described as a 'look', which commonly involved a loss of weight or a pallid complexion. The 'look' of frailty was combined in their expressions, however, with references to an absence of physical strength. Frail people were commonly referred to as weak, breakable or wobbly (i.e. not steady on their feet). When asked about how they understood the concept, the women replied as follows:

Frailty is frailty physically, I think frailty is someone whose bones may crack, ... someone who is slightly bent over and they, when they walk, it's as though they're not sure their feet are going to find that solid ground there ... [a person has] pallid complexion [and is] withdrawn ... not want[ing] to be a bother yet here I am. I am no longer able to take care of myself. I'm at the mercy of ... (Annie).

You've got to be small and skinny. If you want to see frail people, you'll see them down there [speaking about a community service centre] - one little woman, she walks on tippy toes like this ... she is frail. ... and there's a woman there, a big tall woman, and do you know how many pounds she weighed? Eighty-six pounds; she's nothing but skin and bones ... I felt like saying, 'You look awful,' that's what I felt like telling her ... She's so poor. ... They are very thin, and they don't eat very well. They usually don't eat very well (Margaret).

In these accounts, 'frailty' both refers to real problems and needs (e.g. nutrition and risk) and expresses value statements of pity, shame or disgust. Frailty was generally articulated in negative terms, being defined as an inability to do things, as not strong, and not in charge. Both of the quotations reveal connections with the body, size, strength and power. The physical descriptions were matched, however, with descriptions of character or faults. Take for example the values of helplessness ('mercy'), pity ('poorly') and irresponsibility ('not eating well') in the extracts. It is 
important to place these comments in the actual context wherein an older woman is denied the status of competent and independent because she is 'frail'. Consider the following elaboration:

[A frail person is] someone who isn't strong, first of all, someone who doesn't have a lot of emotional resources. I think [of] someone who has frailty as someone [who] is needing, who [needs] to be taken care of. They don't have the resources themselves, they haven't found the resources themselves ... I think of someone who is dependent, who is at risk and all ... of deteriorating, week by week, becoming more and more isolated (Annie).

Building on their descriptions of physical frailty, the older women's narratives turned to social experiences such as death, crisis or difficulties, with, for example, references to illness and hardship, as well as everyday struggles in negotiating their social contexts and physical environments. Their expressions suggest a link, not with age but with particular experiences such as illness. The women's responses indicate that frailty may be about preparing for death, being ill or simply 'worn out'.

If you are ill, you're frail. ... If, if you can't walk on your own, you're frail; if you can't eat by yourself, you're frail; that to me is frail. I don't think it's anything to do with age, I would say that most frail people are older people, your body is worn out: you're frail. My mother died, she was Ior; she was frail when she died. She was small. I'm short too, but I'm chubby and when you're thin and, and you can't move, you can't do things: you're frail. That to me is, is being frail (Martha).

Well, I guess, if you have a stroke, a lot of our friends are having strokes. Some of them, have cancer, and after the cancer treatment, although they're well, they're not as active. ... I think it's the same in every nationality.... You have to be ambulant to enjoy life. Once you're not ambulant and you have a walker to walk, then you really feel, like, old (Kumiko).

At other times, frailty was connected to the emotional vulnerability associated with a particular experience. In these cases, the expressions ranged from those of unfulfilled wishes or desires, to those of loss and unmet need. Instead of rejecting the concept of frailty, the women tended to speak of moments where they 'felt' frail. These were quite different, however, from the earlier physical descriptions. For example, Annie spoke about her daughter's death, while Dorris used frailty to describe her identity during an illness. In both stories, frailty was connected with vulnerability and uncertainty. These examples describe the connections between frailty, social experiences, health-care system attributes (such as rationing) and emotional vulnerability. In all cases, there seems to have been a loss of control over their particular circumstances.

I'd look in the mirror and my face was hanging down. ... I used to look in the mirror and say 'you are so old and you are so frail' ... you look weak and you 
look tired and that's exactly the way you feel. ... I couldn't make my own bed. I used to stand and try to do the dishes ... I didn't cook very much because I didn't want to (Dorris).

Well, I think a lot of the frailty part too, [it] really comes in because of how the government got into this position. ... There's nowhere there that you can go anymore, for health services ... and you may be expecting and looking forward to get[ting] some help from the CLSC and it's not there. ... I mean that can affect people badly and it will make [someone] who wasn't even frail, frail. That is a very, very big part of the factor, because if you can't get out to do certain things, because of, whatever, financial position, or whatever. It's not there, it's not there (Maizie).

Older women's descriptions also showed that frailty is not only a physical description and an emotional experience but also a socially-constructed concept. They understood the distinction between a real condition, state or need, and the way that bodily 'markers' (e.g. impairment) might be perceived and constructed as 'frailty'. Two of the women commented specifically on the social constructions. Elizabeth called frailty 'a way of talking', while Margaret said, 'it's not something you say about yourself; it's something others say about you'. Such perceptivity underlined the complexity of the concept of frailty. It is not only about the physical descriptions and difficult experiences (e.g. death, disability, illness), but also the judgements and negative assumptions of powerlessness and dependence. Consider the way in which Margaret construed the term and its usage:

They don't tell you that they are frail [rather] you notice that they're frail. ... Somebody says, 'Oh, she's a frail little thing', they'll say, 'I'm sorry for all them, because they are so frail', you see. This, it's a description, actually, of a person, [like] she's a very robust person, or a very fat person, she's very frail. ... I can point out to you all the frail people when you see them (Margaret).

\section{Dividing practices: home-care assessment in Québec}

We now turn to care practice as a discursive location for frailty and particularly to its underlying assumptions. Public home-care services in Québec exemplify the western organisational practice of using frailty to assess eligibility for and to allocate services. These processes illustrate 'dividing practices' and the attendant problems (Foucault I982). ${ }^{\mathbf{1 1}}$ In Québec, multi-disciplinary professionals (i.e. case managers) use a standard assessment tool known as the multi-clientele to identify risk (i.e. functional impairment and 'loss of autonomy') and to allocate clients to various public services (Régie Régionale de la Santé et des Services Sociaux de Montréal-Centre 2002). The assessment features mobility 
problems (assigned the highest priority), advanced age, difficulties with personal care, impaired daily-living skills, falls, hospitalisation, unstable medical conditions, medication, malnutrition, cognitive level, family or social situation, and financial situation. ${ }^{12}$ Through the assessment process, an older person moves from being a potential client to someone described as 'frail'. Such clinical judgements are recorded in case files and discussed at inter-disciplinary meetings. While only at-risk persons are eligible for services (i.e. those with sufficient loss of autonomy to be described as 'frail'), eligibility and need have to be balanced with available resources. While being considered 'frail' does not guarantee access to service support, the designation certainly facilitates access.

Through such organisational practices, the concept of frailty is integrated into the professional discourse, verbal exchanges and written notes of home-care workers. Before and after the assessment process, the older person 'at risk' often comes to be known and described as 'frail' during the case presentations for allocating services (i.e. team allocation meetings), during informal discussions between workers (i.e. in the corridors of the institution), and in the case files. While the use of 'frail' prior to assessment seems to reflect advocacy for a rapid assessment and the immediate provision of services, its use after assessment seems to reflect a worker's attempts to keep the file open (i.e. to maintain services). In both cases, the use of frailty is used to qualify 'need' in conjunction with service guidelines (e.g. priority according to greatest risk). During this process, the older person is relatively uninvolved, is objectified (or classified) as 'frail', and becomes eligible for available aids and treatment (e.g. bath-bars, baths, falls prevention measures). Most interventions and treatments focus on mobility - the implicit connections with risk, death and the end-of-life are unspoken (Grenier 2004).

\section{Conceptualisations of frailty: consensus and tensions}

The discursive locations of frailty and its articulation in care practice evince both the overlaps and tensions between biomedical concepts and lived experiences, the negative underlying assumptions of powerlessness, and the 'subjugated knowledge' of people's social and emotional experiences that are mostly invisible in the professional classifications of functional risk. A visible sign or observable state is referenced in all discursive locations and becomes the 'object' of the professional and nonprofessional gaze. This objectification is evident in both Fried and Watson's (1999) claim that clinicians can easily distinguish a frail older person, and in Margaret's expression, 'it's something others say about you'. 
While judgements primarily about the bodies of older people take precedence in professional care-practice, older women's lived experiences point to the personal interpretations of physical changes. Such tensions challenge whether frailty is located in the body or in personal and emotional experiences. This is reflected in ambivalence about whether frailty is based on age (e.g. more than 85 years), an impairment (e.g. a functional criterion such as hip fracture, or an epidemiological criterion such as co-morbidity), or a socially- and emotionally-defined state (e.g. an inaccessible environment, or loss of motivation associated with physical changes). Moving beyond mere recognition (as in the social science literature) of the inherent powerlessness implicit in the definition of frailty in both the OED and in clinical practice, older women's accounts clearly articulate the locations of this loss by reference to the implications of both physical change (e.g. 'not being able to do things like before') and the endof-life (e.g. Elizabeth's 'you get there in the end'). While such socially- and emotionally-defined experiences are subjugated in the dominant discourse, they are the primary themes in older women's accounts. Nonetheless, it is the dominant conceptualisations that shape the context of care, organisational practices, social representations and the lived experiences of older people.

\section{The shape of frailty in health and social-care practice}

The linguistic practices that use 'frailty' to inform care practice and lived experiences are problematic in five ways. First, they give precedence to the physical, observable and functional notions of ill-health and decline, which tend to a narrow medical construction. Second, they assume the preeminence of a service-driven professional assessment of impairment (e.g. standard tick-boxes) that overlooks the social and emotional experiences which accompany functional changes in the body during later life. Such practices fail to recognise that older people may struggle more with the implications of a change than with the physical change itself. Third, this understanding of frailty, applied in a culture of management and fiscal restraint, is used to ration treatment to those at greatest risk, which places older people in competition for scarce resources (for discussions of rationing see Bourgeault et al. 200I; Mariner 1995). Fourth, the current concept overlooks and obscures the way frailty is structured by cumulative disadvantage (e.g. poverty and poor health across the lifecourse), as well as how the experience and interpretations of functional impairment may vary by social location (e.g. age, gender, ethnicity, 'race' and sexual orientation) (Calasanti i996; Grenier 2005). Fifth, reflecting the western 
emphasis on independence and the negative social valuation of its loss, the concept of frailty is reminiscent of earlier notions such as dependency, and similarly connotes blame, burden and pity (Walker ig82). Such problems beg the question of the relevance of frailty to the care of older persons.

\section{The relevance of frailty to the care of older people}

The usage of frailty in Western care practice exposes the tensions between preventive approaches, which aim to prevent adverse outcomes in health and wellbeing across the life-course, and target services on those with the greatest needs and risks. The primary application of frailty in current medicine and care-management has far from preventive aims, but rather corresponds with increased professionalism and efforts to ration care, which perversely conflicts with both recent constructions of 'healthy' or 'successful' ageing (Richardson 2006) and government initiatives to promote the inclusion of older people in society in meaningful ways. ${ }^{13}$ Placing administrative needs before those of older people, it is inconsistent with the humanistic and ethical notions of care that emphasise the ways in which disability and decline are experienced in society rather than the mere presence of impairment (Gilligan I982; Morris I99I; Oliver I990; Swain et al. 2004; UPIAS i976). It does little to deter the social exclusion of already marginalised groups of older people (Aronson and Neysmith 200I), and undermines the prevention rhetoric that pervades programme policies and organisational practices.

The findings of this study suggest that if, as the older women's accounts recommended, the socially- and emotionally-located expressions of frailty were more widely recognised, it might less frequently be thought of as primarily a negative experience of rupture and decline. If 'well-ageing' or 'healthy-ageing' are to be achieved, these subjective indicators of perceived health must be recognised and accounted for. To encourage this change, it is suggested that practice should focus on the prevention of frailty and address the feelings of loss that accompany physical decline, rather than reinforce the feelings and experiences which render someone 'frail' ${ }^{14}$ Focusing, as we do now, on only the worst case of 'frail' persons is an unsustainable model of care. In such a system, those who are classed as 'frail' may be restricted to people with progressively more severe and numerous chronic impairments - the most costly to support and treat. The associations between increasing longevity and increasing costs are a problematic basis upon which to design a care system (Bortz I997; Gee 2000). More importantly, older women's perspectives reveal that the 'making meaning' of the physical changes should be integrated into home-care practice. This 
requires an approach that focuses on both the physical realities and the understanding and interpretations of health events.

\section{Conclusions : experiences of frailty and current care models}

Three sources of evidence have informed this exegesis of frailty and provided understanding of its competing and overlapping conceptualisations, but the study also has gaps and has introduced bias. An analysis focused on 'dividing practices' and 'subjugated knowledge' does not provide a comprehensive analysis of the discourse in question, nor does it control for alternate explanations outside language and practice (Foucault i98o, I982). It can merely bring hidden dimensions of the everyday to light, and invoke critical questioning of the linguistic and associated power processes. Further, the presented evidence has given voice to older women's experiences but not accorded professionals the same opportunity.

This research emanated from the observation that in care practice, older women were labelled as 'frail little old ladies' in case meetings and files. Moving away from care practice, it has examined the usage of frail and frailty in the three locations. Meanings of the terms in the OED, research literature and older women's accounts have proved useful in understanding the discourse of frailty, and the understanding has led back to practice - it has informed an interrogation of organisational practices, elucidated the way in which frailty is embedded in managed-care models, and has explicated its dominant international usage and referents. The process and findings of this study point to the need for more research on the 'fit' between formal care planning - such as models of care, policy initiatives, and organisational practices - and the personal experiences of older persons for whom the services are intended.

\section{Acknowledgments}

This research was conducted for a doctorate and supported by a fellowship from the Canadian Social Sciences and Humanities Research Council (SSHRG) and by a post-doctoral award of the Fonds Québecois de recherche sur la société et la culture (FQRSG). I thank the older women who were interviewed for their insights about 'frailty', as well as the faculty at the Centre on Social Gerontology (Keele, UK) and the 'Social Theory Discussion Group' at McGill for their comments on earlier drafts. Thank you to Elizabeth Airton, Megan Harvey and Heidi Shapiro for their assistance in preparing this manuscript. I also wish to thank Tony Warnes as Editor and the anonymous reviewers for their detailed suggestions. Earlier versions of this paper were presented in poster form at the Vth European Congress of Gerontology in Barcelona, Spain (July 2-5, 2003) and at the British 
Society of Gerontology annual conference at the University of Northumbria, Newcastle-upon-Tyne, United Kingdom (September 4, 2003).

\section{NOTES}

I The literature on managed-care has a dual character: one body of work explicates the principles and practice of managed-care, the other is a critique of managerialism.

2 The way that the concept of frailty was used in a New York Times article of I989, Helping the frail elderly to cope at home, suggests that by the late 1980 s in the United States, the term had moved into the vernacular.

3 Both the adjective and the noun derive from Old French fraile/frele (French frêle)= Italian fraile, and those from the Latin fragilis [fragile]. See the Oxford English Dictionary, second edition, online at http://dictionary.oed.com/ [Accessed 4 April, 2006].

4 For example, frailty has been referred to as an age-related inability to respond adequately to stress (Bowsher i993; Rockwood, Fox, Stolee, Robertson and Beattie I994), and defined according to the presence of two or more medical or functional issues (nutritional, physical, affective, cognitive, and sensory) (Stawbridge et al. I998). Research indicates that frailty is marked by three or more of the following: unintentional weight loss, self-reported exhaustion, weakness (e.g. grip strength), slow walking speed, and low physical activity (Fried et al. 200I). It is also defined as the 'deterioration [in] musculoskeletal, cardiovascular, metabolic, and immunologic systems, which usually results from a decline in physical activity, either as a result of habit or disease inputs' (Bortz 2002).

5 For example, Taylor discussed how frailty interacts with several aspects of the self: '(I) self-knowledge, including-self concept (what we think we are like), ideal self (what we want to be like or think we ought to be like), self-evaluation (moral assessment of how well we have lived up to what we think we ought to have done or been), and self-esteem (the degree to which we like or dislike ourselves); (2) processes (sources of knowledge, personal/internal and social/interactive) through which the self is developed, maintained and changed; (3) the impact of social structural factors (e.g. age or gender) on self structures and processes; and (4) factors explaining the developmental direction that the evolution of the self takes' (Taylor 1992: 209).

6 Kaufman and Becker (I996) identified three features of the social construction of frailty: how subjective experience is interpreted by or through a medical/social service idiom; how health-care providers, and sometimes family, invoke the language of surveillance or safety and risk reduction as the key to maintaining personal autonomy and independence; and how 'rules' become 'facts'.

7 This begins with being puzzled and adjusting, to becoming stable and integrating a lower level of function with their identity, to recognising the infirmities, and being faced with complex life situations as a result of the loss of independence and signs of impending death (Becker I994: 72).

8 The six women considered frail were referred for the following reasons. Ella was very thin, had had several falls and was over 9o; Clara had had moments of frailty including a fall on the bus and was not able to do things as before, but despite this was a very sturdy woman. Dorris was very ill and had had a very difficult time adjusting - she was referred as psychologically frail. Carrie was a frail woman who did not get out much; the worker believed she was beginning to experience some cognitive impairment. Alice was a spirited woman whose physical health issues prohibited her from participating in services. She had been a care-giver for i3 years and had had a long and difficult recovery from hip-replacement surgery. Margaret had had a severe fall a few years back and had had major difficulties recovering. Here, workers' 
notions reflected dominant eligibility criteria related to physical injuries as a result of falls as well as post-hospital care. Although these women were considered frail, they had only limited involvement with services, making them less frail than others involved at the moment of crisis.

9 In Canada, the delivery of health-care services such as public home-care falls under provincial jurisdiction. Thus, while trends of classification and rationing cut across service delivery in all its provinces, there are regional and provincial variations. The Province of Québec has a public home-care programme with a single point of entry requiring assessment. Montréal is the largest city in the Province of Québec and has a diverse (multi-ethnic) population. The focus on the language and meaning of frailty required that the sample be limited to one language. It would be interesting, however, to conduct a similar case in the same context using the French terms perte d'autonomie and dependence.

Io The selection of this sample was illustrative not representative. The diverse social backgrounds of the older woman reflect the profiles one would expect to see in public care in the urban region of Montréal, Québec, Canada. General population statistics indicate that 27.6 per cent of the general population resident in Montréal were born outside Canada. In the region of Notre-Dame-de-Grâce West, where the study participants were recruited, 37 per cent of the population were born outside Canada. (Agence de développement de réseau locaux de services de santé et de services sociaux 2004)

II The understanding of the assessment process presented in this section is the result of a continuing research programme that is examining front-line practice in public homecare services in Québec. Projects have included a review of case files. evaluations of a standard assessment tool, ethnographic observations, and discussions with home-care workers (FQRSC Managed Care Project 2004-2007).

I2 A copy of this form is available on the website of the Régie régionale de la santé et des services sociaux de Montréal-Centre at http://msssa4.msss.gouv.qc.ca/fr/document/ publication.nsf/fbi43c75eoc27b69852566aaoo64borc/7aeicde4e2e89e9i $85256 \mathrm{da}$ coo56a8ac/\$FILE/AS-75IA\% 2oofficiel.pdf [Accessed i6 October 2006].

I3 Some governments are more explicit in the need to include older people's voices and thus require a different analysis. Those which state that older people's voices must be included could measure how and whether this inclusion is achieved, while those failing to sate such objectives could be encouraged to make the first step in recognising older people and including them in policies.

I4 Specific interventions may include the opportunity to discuss past experiences of caring for parents and relatives at the end of life, meanings of functional impairment, and coming to terms with their own mortality. Interventions may also include dealing with functional impairment through normalisation of private and public spaces (e.g. universal design) or exchange-based services (e.g. car-sharing programs, housing, neighbourhood groceries) that would reveal that disability and decline need not be accompanied by negative consequences or social devaluation. Creative examples can be seen in local examples of neighbourhood housing solutions, car sharing and driving services, and the like.

\section{References}

Agence de développement de réseau locaux de services de santé et de services sociaux (ADRLS4) 2004. Portrait de la population: centre de santé et de services sociaux de Réne-Cassin et Notre-Dame-de-Grâce, Montréal-Ouest [Profile of the Population: The Réne-Cassin et Notre-Dame-deGrâce Health and Social Services Centre, West Montreal]. ADRLS4, Montréal, Québec. 
Alter, G. I995. Trends in old-age mortality in the United States, I900-I935: evidence from railroad pensions. In Kertzer, D. and Laslett, P. (eds), Aging in the Past. University of California Press, Berkeley, California, 328-59.

Armstrong, P. 200o. Heal Thyself: Managing Health Care Reform. Garamond, Aurora, Ontario.

Aronson, J. and Neysmith, S. 200r. Manufacturing social exclusion in the home care market. Canadian Public Policy-Analyses de Politiques, 27, 2, I5 $1-65$.

Atchley, R. C. I99I. The influence of aging or frailty on perceptions and expressions of the self: theoretical and methodological issues. In Birren, J. E., Lubben, J. E., Rowe, J. C. and Deutchman, D. E. (eds), The Concept and Measurement of Quality of Life in the Frail Elderly. Academic, San Diego, California, 207-25.

Baltes, P. B. and Smith, J. 2002. New Frontiers in the Future of Aging: From Succesful Aging of the Young Old to the Dilemmas of the Fourth Age. Keynote paper from the Valencia Forum International Association of Gerontology, April I-4, 2002. Available online at http://www.valenciaforum.com/Keynotes/pb.html [Io February, 2003].

Barbi, E., Caselli, G. and Vallin, J. 2003. Hétérogénéité des générations et âge extrême de la vie: Trajectories of extreme survival in heterogeneous populations. Population, 58, I, $45^{-68 .}$

Barnes, M. and Bennett, G. I998. Frail bodies, courageous voices: older people influencing community care. Health \& Social Care in the Community, 6, 2, I02-I I.

Beck, U. 1992. Risk Society: Towards a New Modernity. Sage, London.

Becker, G. 1994. The oldest old: autonomy in the face of frailty. Fournal of Aging Studies, 8, I, 69-76.

Bortz, W. I993. The physics of frailty. Journal of the American Geriatric Society, 41, I004-8.

Bortz, W. M. I. 1997. An examined life. Fournal of Applied Gerontology, r6, 3, 263-6.

Bortz, W. M. I. 2002. A conceptual framework of frailty: a review. Fournal of Gerontology: Medical Sciences, 57A, 5, 283-8.

Bourgeault, I. L., Armstrong, P., Armstrong, H., Choiniere, J., Lexchin, J., Mykhalovskiy, E., Peters, S. and White, J. 20or. Everyday experiences of implicit rationing: comparing the voices of nurses in California and British Columbia. Sociology of Health and Illness, 23, $5,633-53$.

Bowsher, J., Bramlett, M., Burnside, I. and Gueldner, S. H. I993. Methodological consideration in the study of frail elderly people. Fournal of Advanced Nursing, r8, 6, 873-9.

Branch, L. G., Wetle, T. T., Scherr, P. A., Cook, N. R., Evans, D. A., Hebert, L. E., Masland, E. N., Keough, E. and Taylor, J. O. 1988. A prospective study of incident comprehensive medical home care use among the elderly. American Fournal of Public Health, 78, 3, 255-9.

Brody, K.K, Johnson, R. E., Douglas, R. L., Carder, P. C. and Perrin, N. 2002. A comparison of two methods for identifying frail medicare-aged persons. Fournal of the American Geriatrics Society, 5o, 3, 562-69.

Brown, M., Sinacore, D. R., Binder, E. F. and Kohrt, W. M. 200o. Physical and performance measures for the identification of mild to moderate frailty. Fournals of Gerontology, 55A $\mathbf{A}, 6$, 350-5.

Calasanti, T. M. I996. Incorporating diversity: meaning, method, and levels of research. The Gerontologist, 36, 2, I47-56.

Campbell, A.J. and Buchner, D. M. 1997. Unstable disability and the fluctuations of frailty. Age and Ageing, 26, 4, 315-18.

Eales, J., Keating, N. and Damsma, A. 200r. Seniors' experiences of client-centred residential care. Ageing EO Society, 2 I, 3, 279-96.

Edinburgh, G. M. and Aldredge, P. I995. Managed cared. In Edwards, R. L. (ed.), Encyclopedia of Social Work. Volume 2, I9th Edition, National Association of Social Workers, Silver Spring, Maryland, I199-213.

Foster, A. I991. Are cohort mortality rates autocorrelated? Demography 28, 4, 6r9-37. 
Foucault, M. I972. The Archaeology of Knowledge. Translator A. M. Sheridan Smith, Pantheon, New York (First published as L'archéologie du savoir, Gallimard, Paris, I969).

Foucault, M. 1980. Power/Knowledge: Selected Interviews and Other Writings, 1972-1977. Pantheon, New York (Translator and editor C. Gordon).

Foucault, M. 1982. Afterword: the subject and power. In Dreyfus, H. and Rabinow, P. (eds), Michel Foucault: Beyond Structuralism and the Hermeneutics. University of Chicago Press, Chicago, 208-26.

Foucault, M. I994a. Genealogy and social criticism. In Seidman, S. (ed.), The Postmodern Turn: New Perspectives on Social Theory. Cambridge University Press, Cambridge, 39-45.

Foucault, M. I994b. The Order of Things: An Archaeology of the Human Sciences. Vintage, New York.

Fried, L., Tangen, C., Walston, J., Newman, A., Hirsch, C., Gottdiener, J., Seeman, T., Tracy, R., Kop, W., Burke, G. and McBurnie, M. 200I. Frailty in older adults: evidence for a phenotype. Fournal of Gerontology, 56A, 3, I46-57.

Fried, L. and Walston, J. I999. Frailty and the failure to thrive. In Hazzard, W. (ed.), Principles of Geriatric Medicine and Gerontology. McGraw Hill, New York, I387-402.

Fries, J. F. I980. Aging, natural death and the compression of morbidity. New England Journal of Medicine, 303, 3, 130-5.

Gadow, S. I986. Frailty and strength: the dialectic of aging. In Cole, T. R. and Gadow, S. A. (eds), What Does it Mean to Grow Old? Reflections from the Humanities. Duke Univeristy Press, Durham, North Carolina, 237-43.

Gee, E. M. 2000. Population and politics: voodoo demography, population aging, and Canadian social policy. In Gee, E. and Gutman, G. (eds), The Overselling of Population Aging: Apocalyptic Demography: International Challenges and Social Policy. Oxford University Press, Oxford, 5-25.

Gillick, M. 2001. Pinning down frailty. Fournal of Gerontology: Medical Sciences, 56A, 3, Mi34-5.

Gilligan, C. I982. In a Different Voice: Psychological Theory and Women's Development. Harvard University Press, Cambridge, Massachusetts.

Grenier, A. 2004. Older women negotiating uncertainty in everyday life: contesting risk management systems. In Davies, L. and Leonard, P. (eds), Critical Social Work in a Corporate Era: Practices of Power and Resistance. Ashgate, Aldershot, Hampshire, I09-27.

Grenier, A. 2005. The contextual and social locations of older women's experiences of disability and decline. Fournal of Aging Studies, r 9, 2, I3 ${ }^{-}-46$.

Grenier, A. and Hanley, J. 2007. Older women and 'frailty': aged, gendered and embodied resistance. In Arber, S., Andersson, L. and Hoff, A. (eds), Current Sociology, 55, 2, forthcoming.

Hamerman, D. I999. Toward an understanding of frailty. Annals of Internal Medicine, I 30, II, 945-50.

Jones, D. M., Song, X. and Rockwood, K. 2004. Operationalizing a frailty index from a standardized comprehensive geriatric assessment. Fournal of the American Geriatrics Society, 52, II, I929-33.

Kane, R. 2000. Long-term case management for older adults. In Kane, R. L. and Kane, R. A. (eds), Assessing Older Persons: Measures, Meaning and Practical Applications. Oxford University Press, New York, 438-57.

Katz, S. 1996. Disciplining Old Age: The Formulation of Gerontological Knowledge. University Press of Virginia, Charlottesville, Virginia.

Kaufman, S. R. 1994. The social construction of frailty: an anthropological perspective. Fournal of Aging Studies, 8, I, 45-58.

Kaufman, S. R. and Becker, G. I996. Frailty, risk and choice: cultural discourses and the question of responsibility. In Smyer, M., Schaie, K. W. and Kapp, M. B. (eds), Older Adults' Decision-making and the Law. Springer Publishing Company, New York, 48-80. 
Lustbader, W. 2000. Thoughts on the meaning of frailty. Generations, 23, 4, 2I-4.

Manton, K. G. and Stallard, E. 1984. Recent Trends in Mortality Analysis. Academic, Orlando, Florida.

Mariner, W. K. 1995. Rationing health care and the need for credible scarcity: why Americans can't say no. American Fournal of Public Health, 85, Io, I439-45.

Markle-Reid, M. and Browne, G. 2003. Conceptualizations of frailty in relation to older adults. Fournal of Advanced Nursing, 44, I, 58-68.

Means, R., Richards, S. and Smith, R. 2003. Community Care: Policy and Practice. Palgrave Macmillan, Basingstoke, Hampshire.

Michel, D.J. P. 200I. La fragilité est-elle un critère utile? [Frailty: Is it a Useful Criterion?]. Paper presented at the Conferences scientifiques en geriatrie, Livingston Hall, Montreal General Hospital, Montréal, Québec.

Morley, J. E., Perry, H. M. and Miller, D. K. 2002. Something about frailty. Fournal of Gerontology: Medical Sciences, 57A, I I, M698-704.

Morris, J. I99. Pride Against Prejudice. Women's Press, London.

Neysmith, S. and MacAdam, M. I999. Controversial concepts. In Neysmith, S. (ed.), Critical Issues for Social Work Practice with Aging Persons. Columbia University Press, New York, $\mathrm{I}-26$.

Oliver, M. I99o. The Politics of Disablement. Macmillan, Basingstoke, Hampshire.

Raphael, D., Cava, M., Brown, I., Renwick, R., Heathcote, K., Weir, N., Wright, K. and Kirwan, L. 1995. Frailty: a public health perspective. Canadian Fournal of Public Health - Revue Canadienne de Santé Publique, 86, 4, 224-7.

Régie Régionale de la Santé et des Services Sociaux de Montréal-Centre 2002. Multiclientele: autonomy assessment. Montréal-centre. Ministère de la Santé et des Services Sociaux, Québec.

Richardson, S. 2006. I May Be Frail but I Ain't No Failure. Presentation at the first bioethics meeting of the Newman Centre of McGill University, McGill University Health Centre, Montreal, Quebec. 2o January.

Robine, J. M., Herrmann, F. R., Osiek, A., Cos, M. and Michel, J. P. 2005. Frailty judgement by hospital team members: degree of agreement and survival prediction. Fournal of the American Geriatrics Society, 53, 5, 916-7.

Rockwood, K, Fox, R. A., Stolee, P., Robertson, D. and Beattie, B. L. I994. Frailty in elderly people: an evolving concept. Canadian Medical Association Fournal, I5o, 4, 489-95.

Rockwood, K., Stolee, P. and McDowell, I. I996. Factors associated with institutionalization of older people in Canada: testing a multifactorial definition of frailty. Fournal of the American Geriatrics Society, 44, 5, 578-82.

Rubenstein, L. Z., Josephson, K. R., Wieland, G. D., English, P. A., Sayre, J. A. and Kane, R. L. I984. Effectiveness of a geriatric evaluation unit: a randomized clinical trial. New England Fournal of Medecine, 3, II, I664-70.

Sage, W. M., Hurst, C. R., Silverman, J. F. and Bortz, W. M. ig87. Intensive care for the elderly: outcome of elective and non elective admissions. Fournal of the American Geriatrics Society, 35, 4, 312-8.

Schmaltz, H. N., Fried, L. P., Xue, Q., Walston, J., Leng, S. X. and Semba, R. D. 2005. Chronic cytomegalovirus infection and inflammation are associated with prevalent frailty in community-dwelling older women. Fournal of the American Geriatrics Society, 53, 5, 747-54.

Schirm, V. I989. Functionality impaired elderly: their need for home nursing care. Fournal of Community Health Nursing, 6, 4, I99-207.

Shortell, S. M. and Kaluzny, A. D. (eds) 1994. Health Care Management: Organizational Behaviour and Design. Delmar, Albany, New York.

Strawbridge, W.J., Shema, S. J., Balfour, J. L., Highby, H. R. and Kaplan, G. A. I998. Antecedents of frailty over three decades in an older cohort. Fournal of Gerontology: Social Sciences, 53B, I, S9-16. 
Studenski, S., Hayes, R. P., Leibowitz, R. Q., Bode, R., Lavery, L., Walston, J., Duncan, P. and Perera, S. 2004. Clinical global impression of change in physical frailty: development of a measure based on clinical judgment. Fournal of the American Geriatrics Society, 52, 9, $1560-6$.

Swain, J., French, S., Thomas, C. and Barnes, C. 2004. Disabling Barriers: Enabling Environments. Second edition, Sage, London.

Taylor, B. C. 1992. Elderly identity in conversation. Communication Research, I 9, 4, 493-515.

Union of the Physically Impaired Against Segregation (UPIAS) I976. Fundamental Principles of Disability. UPIAS, London.

Vaupel, J. W. I988. Inherited frailty and longevity. Demography, 25, 2, 277-87.

Vaupel, J. W. and Yashin, A. I. I985. Heterogeneity's ruses: some surprising effects of selection on population dynamics. American Statistician, 39, 3, I76-85.

Vaupel, J. W., Manton, K. G. and Stallard, E. I979. The impact of heterogeneity in individual frailty on the dynamics of mortality. Demography, I6, 3, 439-54.

Vaupel, J. W., Yashin, A. I. and Manton, K. G. I988. Debilitation's aftermath: stochastic process models of mortality. Mathematical Population Studies I, I, 2 I-48.

Vellas, B., Guillet-Guyonnet, S., Nourhashemi, F., Rolland, Y., Lauque, S., Ousset, P. J., Moulias, S., Andrieu, S., Fontan, B., Adoue, D., Lafont, C., Baumgartner, R., Garry, P. and Albarede, J. L. 2000. Falls, frailty and osteoporosis in the elderly: a public health problem. La Revue Médecine Interne, 2 I, 7, 608-13.

Walker, A. I982. Dependency and old age. Social Policy and Administration, 16, 2, I15-35.

World Health Organisation 2002. The World Health Report 2002: Reducing Risks, Promoting Healthy Life. United Nations Organisation, New York.

Yashin, A. I. and Iachine, I. A. I997. How frailty models can be used in evaluating longevity limits. Demography, 24, I, $3^{\mathrm{I}-48}$.

Accepted 20 October 2006

Address for correspondence:

Amanda Grenier, School of Social Work, McGill University, 3506 University Street, Wilson Hall Room 300, Montreal, Quebec $\mathrm{H}_{3} \mathrm{~A}_{2} \mathrm{~A}_{7}$, Canada.

E-mail: amanda.grenier@mcgill.ca 